Proceedings of SALT 27: 191-211, 2017

\title{
Ambiguous than-clauses and the mention-some reading*
}

\author{
Linmin Zhang \\ Concordia University
}

\author{
Jia Ling \\ New York University
}

\begin{abstract}
This paper addresses the ambiguity of comparatives that contain a permission-related existential modal in their than-clause. For example, given the context that the interval of permitted speed is between 35 and $50 \mathrm{mph}$, the sentence Lucinda is driving less fast than allowed is ambiguous between two readings: (i) her speed is below the minimum (i.e., $35 \mathrm{mph}$ ); (ii) her speed is below the maximum (i.e., $50 \mathrm{mph}$ ). Previously, this ambiguity has been attributed to either the scopal interaction between a negation element and a modal (Heim 2006a) or the optional application of a silent operator (Crnič 2017). Here we show that these two lines of accounts under- or over-generate. Instead, we propose that the source of this ambiguity is located in the ambiguous answerhood for wh-questions corresponding to this kind of than-clauses (e.g., how fast is Lucinda allowed to drive). The current proposal consists of three parts. First, based on Zhang \& Ling 2015, 2017a,b, we adopt a generalized interval-arithmetic-based recipe for computing the semantics of comparatives. Second, the semantics of than-clauses is considered equal to that of short answers to corresponding $w h$-questions. Third, since the use of existential priority modals in $w h$-questions leads to the 'mention-some/mention-all' ambiguity for answerhood, we propose that this ambiguity projects in further derivation and leads to the two readings for comparatives like the Lucinda sentence.
\end{abstract}

Keywords: clausal comparatives, interval arithmetic, permission-related modals, answerhood for $w h$-questions, mention-some/mention-all ambiguity, existential priority modals

\section{Introduction}

It has been noticed for decades (since Seuren 1979) that some comparatives are ambiguous. For example, as illustrated in (1), given this context in which the permissible speed ranges from $35 \mathrm{mph}$ to $50 \mathrm{mph}$, sentence (1) has two readings.

One interpretation is that Lucinda is driving below the required minimum speed, which suggests that Lucinda's speed is illegal (see (1a) - the ' $<$ MIN' reading). The other interpretation is that Lucinda is driving below the speed limit, which suggests that Lucinda's speed is legal (see $(1 \mathrm{~b})$ - the ' $<$ MAX' reading).

* Thanks to Alan Bale, Chris Barker, Lucas Champollion, Danny Fox, Daniel Lassiter, Rick Nouwen, Robert Pasternak, Anna Szabolcsi, and the audience and reviewers of the 20th Amsterdam Colloquium (2015) and SALT 27 for comments, discussions, and suggestions!

C2017 Zhang and Ling 
(1) CONTEXT: This highway has a required minimum speed of $35 \mathrm{mph}$ and a speed limit of $50 \mathrm{mph}$.

Lucinda is driving less fast than allowed.

Lucinda sentence

a. ' $<$ MIN' reading

$\sim$ Lucinda's speed is illegal.

Lucinda is driving below the required minimum speed (i.e., $35 \mathrm{mph}$ ).

b. ' $<$ MAX' reading $\quad \sim$ Lucinda's speed is legal.

Lucinda is driving below the speed limit (i.e., $50 \mathrm{mph}$ ).

There are two elements noticeable about the Lucinda example in (1). First, this is a less-than comparative, not a more-than comparative. Second, its than-clause contains a permission-related existential modal: allowed. Therefore, these elements suggest several potential ways to locate the source of ambiguity for sentence (1).

Since the work of Rullmann (1995), several studies (e.g., Heim 2006a; Büring 2007a,b) have focused on the differences between more-than and less-than comparatives. In particular, Heim (2006a) decomposes less into a negation element (i.e., little) and a comparative morpheme (i.e., -er) and attributes the ambiguity of sentence (1) to the scopal interaction within its than-clause.

Alternatively, based on a degree-plurality-based approach to the semantics of comparatives (Beck 2010, 2013, 2014; Dotlačil \& Nouwen 2016), Crnič (2017) attributes the ambiguity of sentence (1) to the optional application of a silent operator.

In addition to these two approaches, relevant data have been discussed by Meier (2002), Heim (2006b), Krasikova (2008, 2011), Beck (2010, 2013), and Alrenga \& Kennedy (2014), and inferential properties of predicates as well as pragmatic factors have also been taken into consideration (see Beck \& Rullmann 1999; Beck 2013).

The goal of this paper is to point out a new source of ambiguity: the 'mentionsome/mention-all' ambiguity in answering wh-questions containing existential priority modals (see Fox 2013, 2016; Xiang 2016; Dayal 2016).

In a nutshell, we consider the semantics of a than-clause equal to that of the short answer to the wh-question corresponding to its than-clause, and thus, when the answerhood for this $w h$-question is ambiguous due to the use of existential priority modals, this ambiguity projects in further derivation.

In the following, Section 2 presents two representative existing accounts (Heim 2006a and Crnič 2017) and their limitations. Section 3 presents more data to show the general pattern of ambiguous and unambiguous comparatives. Our proposal in Section 4 includes three parts: a generalized interval-arithmetic-based recipe for the semantics of comparatives (Section 4.1), an answerhood-based view for the semantics of than-clauses (Section 4.2), and an account that attributes the ambiguity of 'mention-some/mention-all' answerhood to the use of existential priority modals (Section 4.3). Section 5 assembles these parts and accounts for the ambiguity of the Lucinda example. Section 6 concludes the paper. 
Ambiguous than-clauses and the mention-some reading

\section{Previous accounts and their limitations}

\subsection{Heim's (2006a) account for the ambiguity of less-than comparatives}

Heim (2006a) attributes the ambiguity of sentence (1) to the scopal interaction between little (i.e., a negation element) and a modal within the than-clause.

In this analysis, as shown in (2), less is considered composed of two parts: little and comparative morpheme more/-er. Heim (2006a) analyzes little as an operator that basically works like a negation element: it takes a certain degree (of type $d$ ) as input and returns a degree generalized quantifier (see (3)).

$$
\begin{aligned}
& \text { less }=\text { little }+ \text { more/-er } \\
& {\left[\left[\text { little }_{\text {Heim (2006a) })]}\right]\langle d,\langle d t, t\rangle\rangle \stackrel{\text { def }}{=} \lambda d_{d} \cdot \lambda P_{\langle d t\rangle} \cdot P(d)=0 \quad \approx\right. \text { negation }}
\end{aligned}
$$

Therefore, in Heim's (2006a) analysis for sentence (1), - er in the matrix clause relates two negated degree properties (see (6)): the comparative standard (which is expressed by the than-clause) and the comparative subject (i.e., the set of speeds that Lucinda does not reach $-\left(\operatorname{Speed}_{@}(\right.$ Lucinda $\left.\left.),+\infty\right)\right)$. As shown in (7), the comparative standard is ambiguous between (i) the set of speeds Lucinda is allowed not to reach, which leads to the ' $<$ MIN' reading (see (7a)), and (ii) the set of speeds Lucinda is not allowed to reach, which leads to the ' $<$ MAX' reading (see (7b)).

$$
\begin{aligned}
& {\left[\left[\text { fast }_{\text {Heim (2006a) }}\right]_{\langle d, e t\rangle} \stackrel{\text { def }}{=} \lambda d_{d} \cdot \lambda x_{e} \cdot \operatorname{Speed}_{\langle e d\rangle}(x) \geq d\right.} \\
& {\left[\left[\text { more/-er }_{\text {Heim (2006a) }}\right]_{\langle d t,\langle d t, t\rangle\rangle} \stackrel{\text { def }}{=} \lambda P_{\langle d t\rangle} \cdot \lambda Q_{\langle d t\rangle} \cdot P \subset Q\right.}
\end{aligned}
$$

Heim's (2006a) LF for the matrix clause of (1):

Lucinda is driving [[-er than allowed] little] fast

[-er than-clause $]_{\langle d t, t\rangle}\left[\lambda d_{1} \text {. [[ } d_{1} \text { little }_{\langle d,\langle d t, t\rangle\rangle}\right]_{\langle d t, t\rangle}\left[\lambda d_{2}\right.$.Lu is driving $d_{2}$ fast $\left.\left.]\right]\right]$

The scopal interaction between allowed and little within the than-clause: Heim's (2006a) LF for the than-clause of (1):

than (Lucinda is) allowed (to drive [... little] fast)

a. LF for the than-clause with 'allowed > little':

$\lambda d_{3}$. allowed [[ $\left.d_{3} \operatorname{little}_{\langle d,\langle d t, t\rangle\rangle}\right]_{\langle d t, t\rangle}\left[\lambda d_{4}\right.$. Lucinda is to drive $d_{4}$ fast $\left.]\right]$ $\sim$ the set of speed degrees that Lucinda is allowed not to reach.

(the required min., $+\infty) \subset\left(\operatorname{Speed}_{@}(\right.$ Lucinda $\left.),+\infty\right)$ ' $<$ MIN' reading

b. LF for the than-clause with 'little $>$ allowed':

$\lambda d_{3}$. [[ $\left[d_{3} \operatorname{little}_{\langle d,\langle d t, t\rangle\rangle}\right]_{\langle d t, t\rangle}\left[\lambda d_{4}\right.$. Lucinda is allowed to drive $d_{4}$ fast $\left.]\right]$ $\leadsto$ the set of speed degrees that Lucinda is not allowed to reach.

(the speed limit, $+\infty) \subset\left(\operatorname{Speed}_{@}(\right.$ Lucinda $\left.),+\infty\right) \quad$ ' $<$ MAX' reading $^{\prime}$

Crucially, this account is based on the presence of little in sentence (1). However, 
as noted by Meier (2002), Heim (2006b), Krasikova (2008, 2011), and Alrenga \& Kennedy (2014), not only less-than comparatives but also more-than comparatives can be ambiguous, as illustrated in (8). It is also worth noting that sentences in (8) use obligation-related universal modals. Under the given context, sentences in (8) all have two readings: the ' $>$ MAX' reading (see (9a)) and the ' $>$ MIN' reading (see (9b)). According to Alrenga \& Kennedy (2014), even though the ' $>$ MIN' reading is more salient, the ' $>$ MAX' reading is still marginally available.

(8) Context: Chuck wants to be a fighter pilot. Air Force regulations require all pilots to be between $5^{\prime} 4^{\prime \prime}$ and $6^{\prime} 5^{\prime \prime}$ tall.
a. Chuck is taller than he needs to be.
b. Chuck is taller than he has to be.
c. Chuck is taller than he is required to be.

(9) The ambiguity of $(8 \mathrm{a}-\mathrm{c})$ :

a. ' $>$ MAX' reading: Chuck is taller than the upper bound (i.e., $6^{\prime} 5^{\prime \prime}$ ).

b. '> MIN' reading: Chuck is taller than the lower bound (i.e., $5^{\prime} 4^{\prime \prime}$ ).

The existence of ambiguous more-than comparatives suggests that an account that relies on the use of less (or little) under-generates attested patterns.

\subsection{Crnič's (2017) account within a degree-plurality-based framework}

For an alternative account, Crnič (2017) attributes the ambiguity of sentence (1) to the optional application of a silent operator.

Crnič (2017) adopts the degree-plurality-based framework developed by Beck (2010, 2013, 2014) and Dotlačil \& Nouwen (2016). Within this framework, the domain of degrees is similar to the domain of entities in that there are not only atomic degrees like $50 \mathrm{mph}, 6^{\prime} 5^{\prime \prime}$, but also degree pluralities like $50 \mathrm{mph} \oplus 51 \mathrm{mph}$, etc. The semantics of than-clauses is analyzed as a potentially plural degree.

Crnič (2017) uses two silent operators: SHIFT and M-INF. Essentially, the application of SHIFT changes the 'at least' reading of a degree expression (see (10)) into an 'exactly' reading (see (11), (12)). M-INF is borrowed from Beck (2014): it applies to a set of degrees to generate the sum of the most informative degrees in this set. Obviously, the output of M-INF is potentially a degree plurality.

$$
\begin{aligned}
& {\left[\left[\text { fast }_{\text {Crnič }}(2017)\right]\right]_{\langle d, e t\rangle} \stackrel{\text { def }}{=} \lambda d_{d} \cdot \lambda x_{e} \cdot \operatorname{Speed}_{\langle e d\rangle}(x) \geq d} \\
& {[[\operatorname{SHIFT}]]_{\langle d,\langle\langle d, e t\rangle, e t\rangle\rangle} \stackrel{\text { def }}{=} \lambda d_{d} \cdot \lambda M_{\langle d, e t\rangle} \lambda x_{e} \cdot \max \left(\lambda d^{\prime} \cdot M\left(d^{\prime}\right)(x)\right) \leq_{\text {part }} d} \\
& {[[[\operatorname{SHIFT} d] \text { fast }] x]} \\
& \Leftrightarrow \max \left(\lambda d^{\prime} \cdot \operatorname{Speed}(x) \geq d^{\prime}\right) \leq_{\text {part }} d \quad \sim \text { an 'exactly' interpretation }
\end{aligned}
$$


Ambiguous than-clauses and the mention-some reading

$$
\begin{aligned}
& [\mathrm{M}-\mathrm{INF}]]_{\langle d t, d\rangle}{ }^{1} \\
& \stackrel{\text { def }}{=} \lambda D_{\langle d t\rangle} \cdot \oplus\left\{d \mid D(d) \wedge \neg \exists d^{\prime}\left(D\left(d^{\prime}\right) \wedge d \neq d^{\prime} \wedge D\left(d^{\prime}\right)>_{\text {more informative }} D(d)\right)\right\}
\end{aligned}
$$
i.e., M-INF takes a degree property $D$ as input and returns the sum of any atomic degree $d$ such that (i) the property $D$ holds for $d$ and (ii) there is no other $d^{\prime}$ that makes $D\left(d^{\prime}\right)$ more informative than $D(d)$.

Thus, when a than-clause does not denote an atomic degree, there are two possibilities: (i) without the application of SHIFT, M-INF returns the maximum value of all relevant degrees; (ii) with the application of SHIFT, M-INF returns the sum of all relevant degrees. For a more-than comparative, as shown in (14)-(17), Lucinda's actual speed is compared either with the maximally allowed degree ' 50 mph' (see (15a)) or each atomic degree in the sum '35 mph $\oplus \ldots \oplus 50 \mathrm{mph}$ ' (see (15b)). Thus, no matter whether SHIFT applies or not, the more-than comparative (14) has an unambiguous ' $>$ MAX' reading. However, for a less-than comparative, these two options lead to the ' $<$ MAX' and ' $<$ MIN' readings respectively (see (18)).

(14) ConteXt: the permissible speed ranges from $35 \mathrm{mph}$ to $50 \mathrm{mph}$. Lucinda is driving faster than allowed. Unambiguous: ' $>$ MAX' reading

(15) Crnič's (2017) LF for the than-clause of (14) / the Lucinda example in (1):

a. M-INF $[\lambda d$. Lucinda is allowed to drive $d$ fast $]$

$$
[[\mathrm{M}-\mathrm{INF}]]\left(\left\{d \mid \diamond_{w}\left(\operatorname{Speed}_{w}(\text { Lucinda }) \geq d\right)\right\}\right) \quad=50 \mathrm{mph}
$$

b. M-INF $[\lambda d$. Lucinda is allowed to drive [SHIFT $d]$ fast]

$$
\begin{array}{r}
{[[\mathrm{M}-\mathrm{INF}]]\left(\left\{d \mid \diamond_{w}\left(\max \left(\lambda d^{\prime} . M\left(d^{\prime}\right)(x)\right) \leq_{\text {part }} d\right)\right\}\right)} \\
=35 \mathrm{mph} \oplus \ldots \oplus 50 \mathrm{mph}
\end{array}
$$

(16) a. $\quad\left[\left[\right.\right.$ more/-er Crnič (2017) $\left._{3}\right]\langle d, d t\rangle \stackrel{\text { def }}{=} \lambda d_{d} \cdot \lambda d_{d}^{\prime} \cdot d^{\prime}>d$

b. $\quad\left[\operatorname{less}_{\text {Crnič (2017) })}\right]_{\langle d, d t\rangle} \stackrel{\text { def }}{=} \lambda d_{d} \cdot \lambda d_{d}^{\prime} . d>d^{\prime}$

(17) $d>d^{\prime}$ iff for all atomic degrees $d_{\text {atom }}, d_{\text {atom }}^{\prime}$,

if $d_{\text {atom }} \leq_{\text {part }} d$ and $d_{\text {atom }}^{\prime} \leq_{\text {part }} d^{\prime}$, then $d_{\text {atom }}>d_{\text {atom }}$.

(18) Crnič's (2017) LF for the Luncinda example in (1):

less [than-clause] [M-INF [ $\lambda d^{\prime}$. Lucinda is driving $d^{\prime}$ fast]]

a. Based on (15a), $50 \mathrm{mph}>\operatorname{Speed}_{@}\left(\right.$ Lucinda). $\sim$ ' $<$ MAX' reading $^{\prime}$

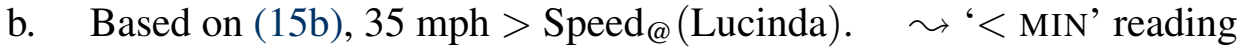

However, as already noticed by Crnič (2017), when a more-than comparative contains a universal (modal or nominal) quantifier in its than-clause, it is predicted to be ambiguous between a '> MIN' and a '> MAX' reading. However, as shown in (19), this prediction is not borne out, and only the a ' $>$ MAX' reading is attested.

1 This operator is named MAX by Crnič (2017). We call it M-INF to avoid confusion. 
(19) Lucinda is driving faster than every boy is.

unambiguous

a. $\quad[[\mathrm{M}-\mathrm{INF}[\lambda d$. every boy is driving $d$ fast $]]]$ : the maximum speed such that every boy reaches $\sim$ Lucinda is faster than the slowest boy is. unattested reading

b. [[M-INF $[\lambda d$. every boy is driving [SHIFT $d]$ fast]]]: the sum of each boy's speed

$\leadsto$ Lucinda is faster than the fastest boy is. available reading

In sum, the accounts of Heim (2006a) and Crnič (2017) under- or over-generate, suggesting that the ambiguity of comparatives like the Lucinda example is, in general, not due to the direction of inequality or the mere presence of some quantifier or modal that makes their than-clause fail to denote an atomic degree.

\section{More empirical observations}

Here we show that comparatives are, in general, unambiguous, and the pattern for MAX- or MIN-related readings is uniform. The only exception comes with the use of deontic modals (especially permission-related existential modals) in than-clauses.

As shown in (21-24), for both more-than and less-than comparatives, when comparatives contain in their than-clause universal nominal quantifiers (see (21)), universal epistemic modals (see (22)), existential nominal quantifiers (see (23)), or existential epistemic modals (see (24)), these sentences are all unambiguous.

Moreover, when a than-clauses denotes a range of values, its reading follows the generalization in (20), which is basically consistent with Beck's (2013) findings.

(20) When a than-clause denotes a range of values (see (21), (22), and (24)),

a. A more-than comparative always has a ' $>$ MAX' reading;

b. A less-than comparative always has a ' $<$ MIN' reading.

(21) Universal nominal quantifier: every

a. John is taller than every girl is. $\quad \checkmark>$ MAX, \# $>$ MIN

b. John is less tall than every girl is. $\quad \#<$ MAX, $\checkmark<$ MIN

(22) Universal epistemic modal: be supposed to

CONTEXT: Air Force regulations require all pilots to be between $5^{\prime} 4^{\prime \prime}$ and $6^{\prime} 5^{\prime \prime}$ tall. John, a fighter pilot, meets the requirement, but we doubt this.

a. John looks taller than he is supposed to be. $\quad \checkmark>$ MAX, \# $>$ MIN

b. John looks less tall than he is supposed to be. \#< MAX, $\checkmark<$ MIN

(23) Existential nominal quantifier: some

a. John is taller than some girls are. \# $>$ MAX, $\checkmark>$ MIN

b. John is less tall than some girls are. $\quad \checkmark<$ MAX, \#< MIN 
Ambiguous than-clauses and the mention-some reading

Existential epistemic modal: possible

CONTEXT: The range of sound frequencies audible to humans has an upper and a lower bound.

a. The call of these birds is higher than it is possible for us to hear.

$$
\checkmark>\text { MAX, \# > MIN }
$$

b. This sound is less high than it is possible for us to hear.

$$
\#<\text { MAX, } \checkmark<\text { MIN }
$$

Here we turn to comparatives with deontic modals in their than-clause that address permission or obligation. As already shown in (1) and (8), comparatives of the patterns (i) 'less-than + permission-related existential modals' or (ii) 'more-than + obligation-related universal modals' are ambiguous. The naturally occurring examples shown in (25) and (26) suggest that both ' $>$ MIN' and ' $>$ MAX' readings can be available for more-than comparatives with permission-related existential modals, though if minimally is omitted, the ' $>$ MIN' reading is not obvious. ${ }^{2}$ However, for less-than comparatives with obligation-related universal modals, as shown in (27), it seems that they only have an unambiguous ' $<$ MIN' reading.

(25) CONTEXT: Chip sets with low heat release may come with small heat sinks, and their cooling efficiency will still be sufficient owing to more intensive heat exchange because of the increased temperature difference. (link)

Northbridge has a larger heat sink than minimally allowed. $\quad \checkmark>$ MIN

(26) It is advisable that a child stays in the seat of group 1 as long as possible, that is until he or she reaches the mass bigger than maximally allowed for this group of seats. (link)

$\checkmark>\operatorname{MAX}$

CONTEXT: All pilots are required to be between $5^{\prime} 4^{\prime \prime}$ and $6^{\prime} 5^{\prime \prime}$ tall.

Chuck is less tall than he needs / has to be. $\quad \#<\operatorname{MAX}, \checkmark<$ MIN

Furthermore, as (28) shows, once an exhaustifier (such as any) is added into the than-clause of comparatives with permission-related existential modals, the resultant sentences are no longer ambiguous and follow the generalization in (20). In contrast, adding an exhaustifier into comparatives with obligation-related universal modals does not change the pattern of judgments shown in (8) and (27): the morethan comparative (29a) is marginally ambiguous with a dispreferred ' $>$ MAX' reading and the less-than comparative (29b) has an unambiguous ' $<$ MIN' reading. ${ }^{3}$

2 Beck (2013) claims that the '> MIN' reading is most salient for than-clauses containing sufficient: e.g., we have more flour than sufficient. This can follow naturally from studies that analyze sufficient as minimally allowed (see Meier 2003; c.f. Hacquard 2005, 2006; Zhang 2017).

3 In fact, this follows naturally from the claim that exhausifiers like any have a universal force (see, e.g., Dayal 2004; Xiang 2016). (Notice that obligation-related modals have also a universal force.) 


\begin{tabular}{c|c|c} 
& Existential modal (allowed) & Universal modal (required) \\
\hline $\begin{array}{c}\text { more than } \\
\text { less than }\end{array}$ & $(25),(26): \checkmark>$ MAX, $\checkmark>$ MIN & $(8): \checkmark ?>$ MAX, $\checkmark>$ MIN \\
\hline \hline & allowed + exhaustifier & (27): \#< MAX, $\checkmark<$ MIN \\
\hline more than & $(28 \mathrm{a}): \checkmark>$ MAX, \# $>$ MIN & $(29 a): \checkmark ?>$ MAX, $\checkmark>$ MIN \\
less than & $(28 \mathrm{a}): \#<$ MAX, $\checkmark<$ MIN & $(29 b): \#<$ MAX, $\checkmark<$ MIN
\end{tabular}

Table 1 Available readings for comparatives with deontic modals.

(28) CONTEXT: This highway has a required minimum speed of $35 \mathrm{mph}$ and a speed limit of $50 \mathrm{mph}$.

a. Bill is driving faster than anyone is allowed to. $\checkmark>$ MAX, \# $>$ MIN

b. Bill is driving less fast than anyone is allowed to. \# $<$ MAX, $\checkmark<$ MIN

(29) CONTEXT: All pilots are required to be between $5^{\prime} 4^{\prime \prime}$ and $6^{\prime} 5^{\prime \prime}$ tall.

a. Chuck is taller than anyone is required to be. $\checkmark$ ? $>$ MAX, $\checkmark>$ MIN

b. Chuck is less tall than anyone is required to be. \# $<$ MAX, $\checkmark<$ MIN

Table 1 summarizes the judgments for comparatives with deontic modals. There are two points worth noting here. First, overall, the generalization in (20) is still compatible with comparatives with deontic modals. Second, it seems that (i) for those using obligation-related universal modals, the MAX-related reading is somehow disfavored, while (ii) for those using permission-related existential modals, the MIN-related reading is sometimes non-obvious (i.e., not unattested). Thus, in general, comparatives with permission-related modals are more subject to ambiguity than comparatives with obligation-related modals, and the original Lucinda example illustrates exactly the most typical type of ambiguous comparatives.

Therefore, the ambiguity of comparatives is crucially related to the use of permission-related modals, and this is obviously reminiscent of another kind of ambiguity in natural language: the mention-some/mention-all ambiguity of answerhood for certain $w$ h-questions. As pointed out by Fox $(2013,2016)$, Xiang (2016), and Dayal (2016), the hallmark of this mention-some/mention-all ambiguity is exactly the use of existential priority modals in $w h$-question (and the absence of exhaustifiers). In the following, we develop an analysis following this line.

\section{Proposal}

Our current proposal is composed of three parts. First, with an interval-arithmeticbased recipe, we show how the maximum and minimum values of a comparative standard (i.e., what is expressed by a than-clause) always contribute to the semantics 
Ambiguous than-clauses and the mention-some reading

of comparatives in a uniform way, and thus comparatives are in principle unambiguous. Next, we draw a connection between the semantics of than-clauses and that of short answers to corresponding $w h$-questions and show that they are equivalent. Therefore, whether a comparative is ambiguous depends solely on whether the $w h$-question corresponding to its than-clause has ambiguous answerhood. Finally, we show that the use of existential priority modals leads to ambiguous answerhood.

\subsection{The semantics of comparatives: An interval-arithmetic-based approach}

A generalized interval-arithmetic-based recipe for computing the semantics of comparatives has been developed by Zhang \& Ling (2015, 2017a,b), which characterizes in a precise and natural way how the maximum and minimum values of comparative standards and differentials contribute to the truth condition of comparatives. ${ }^{4}$

This interval-arithmetic-based recipe is based on two basic ideas. First, a comparative sentence essentially denotes a relation among three degree-related expressions: the comparative subject, the comparative standard, and the differential. For example, for the sentence John is taller than Mary is, here the comparative subject is John's height (e.g., the position that marks ' 6 ' ' on the scale of height), the comparative standard is Mary's height (e.g., the position that marks ' 5 ' on the same scale), and the differential is the distance between John's and Mary's position on this scale. ${ }^{5}$ Notice that the positions (i.e., the comparative standard and the comparative subject) and the distance between them are not the same kind of objects. This becomes evident when we consider the temporal scale: 5:00 and 6:00 are two positions on the temporal scale, while the distance between them is 1 hour, not 1:00.

Second, positions on a scale don't have to be represented by points, and we adopt a generalized view for positions and represent them as intervals. Intervals can be considered somewhat blurred points: an interval is a range of possible values so that it marks a position in a not-so-precise way. Therefore, an interval is actually a convex set of points, ${ }^{6}$ and for a convex set $\{x \mid a \leq x \leq b\}$, we can write it as $[a, b] .{ }^{7}$ As shown in (30), operations on two intervals result in the largest possible range.

4 The differences between this recipe and the interval-based approach of Schwarzchild \& Wilkinson (2002) as well as the degree-plurality-based approach developed by Beck (2014) and Dotlačil \& Nouwen (2016) are discussed in Zhang \& Ling 2015, 2017 b.

5 This distance-based ontology for the semantics of comparatives is different from the classical threshold-exceeding view (see Von Stechow 1984; Schwarzschild 2008; etc), and the differences between these two views are discussed in Zhang \& Ling 2015, $2017 \mathrm{~b}$.

6 A convex totally ordered set is a totally ordered set $P$ such that for any elements $a$ and $b$ in the set, if $a \leq b$, then any element $x$ such that $a \leq x \leq b$ is also in the set. E.g., $\{x \mid x>0\}$ and $\{x \mid 4 \leq x<8\}$ are convex sets, while sets such as $\{x \mid x \leq 5 \vee x>8\}$ are not convex.

7 We use square brackets '[' and ']' to mean closed upper and lower bounds and parentheses '(' and ')' to mean open upper and lower bounds. 


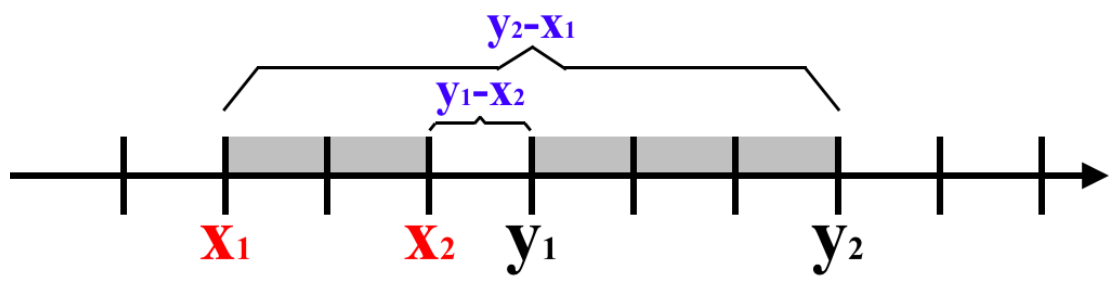

Figure 1 The subtraction between two intervals

$$
\begin{aligned}
& \text { Operations on two intervals }\left[x_{1}, x_{2}\right] \text { and }\left[y_{1}, y_{2}\right]: \quad \text { (see Moore 1979) } \\
& \min \left(\left[x_{1}, x_{2}\right]\langle\mathrm{OP}\rangle\left[y_{1}, y_{2}\right]\right)=\min \left(x_{1}\langle\mathrm{OP}\rangle y_{1}, x_{1}\langle\mathrm{OP}\rangle y_{2}, x_{2}\langle\mathrm{OP}\rangle y_{1}, x_{2}\langle\mathrm{OP}\rangle y_{2}\right) \\
& \max \left(\left[x_{1}, x_{2}\right]\langle\mathrm{OP}\rangle\left[y_{1}, y_{2}\right]\right)=\max \left(x_{1}\langle\mathrm{OP}\rangle y_{1}, x_{1}\langle\mathrm{OP}\rangle y_{2}, x_{2}\langle\mathrm{OP}\rangle y_{1}, x_{2}\langle\mathrm{OP}\rangle y_{2}\right)
\end{aligned}
$$

Based on (30), the definition of the subtraction between two intervals is shown in (31) and illustrated in Figure 1. Obviously, the difference between two intervals $\left[x_{1}, x_{2}\right]$ and $\left[y_{1}, y_{2}\right]$ is also an interval.

$$
\text { Interval subtraction: }\left[y_{1}, y_{2}\right]-\left[x_{1}, x_{2}\right]=\left[y_{1}-x_{2}, y_{2}-x_{1}\right] \quad(\text { See Figure } 1)
$$

Therefore, as shown in (32), for a comparative sentence, we can analyze the three degree-related expressions all as intervals, and the relation between these three intervals follows the rule of interval subtraction in (31). Thus, given the values of the differential and the comparative standard, we can also compute the value of the comparative subject, as shown in (33). Notice that the upper bound of the comparative subject is computed from the lower bound of the comparative standard and the upper bound of the differential (see (33a)), while the lower bound of the comparative subject is computed from the upper bound of the comparative standard and the lower bound of the differential (see (33b)).

$$
\begin{aligned}
& \text { a. differential } \text { upper-bound }_{\text {a }} \\
& =\text { comparative-subject }_{\text {upper-bound }}-\text { comparative-standard }_{\text {lower-bound }} \\
& \text { b. differential } \text { lower-boud }_{\text {low }} \\
& \sim(33 \mathrm{~b}) \\
& =\text { comparative-subject }_{\text {lower-bound }}-\text { comparative-standard }_{\text {upper-bound }} \\
& =\text { comparative-standard }_{\text {lower-bound }}+\text { differential }_{\text {upper-bound }}
\end{aligned}
$$

We analyze the semantics of gradable adjectives as relations between intervals (of type $\langle d t\rangle$ ) and entities (of type $e$ ). As shown in (34), $x$ is situated within the 
Ambiguous than-clauses and the mention-some reading

interval $I$ on a relevant scale. For the absolute use of gradable adjectives, the interval argument is a context-dependent interval $I^{C}$ (see (34a)), which is the shorthand for 'the context-dependent interval such that it is from the lower to the upper bound of being tall for a relevant comparison class'. In (34b), ' 6 ' ' can be interpreted either as a singleton set for an 'exactly' reading (see (34b-i)) or an interval with $6^{\prime}$ as its lower bound for an 'at least' reading (see (34b-ii)).

$$
\begin{aligned}
& {\left[[\text { tall }]_{\langle d t, e t\rangle} \stackrel{\text { def }}{=} \lambda I_{\langle d t\rangle} \cdot \lambda x_{e} \cdot \operatorname{Height}(x) \subseteq I\right.} \\
& \text { a. } \quad[\text { John is tall }] \Leftrightarrow \operatorname{Height}(\text { John }) \subseteq I^{C} \\
& \text { b. (i) } \left.\quad\left[\text { John is } 6^{\prime} \text { tall }\right]\right] \Leftrightarrow \operatorname{Height}(\text { John }) \subseteq\left[6^{\prime}, 6^{\prime}\right] \quad \text { 'exactly' reading } \\
& \text { (ii) } \left.\quad\left[\text { John is } 6^{\prime} \text { tall }\right]\right] \Leftrightarrow \operatorname{Height}(\text { John }) \subseteq\left[6^{\prime},+\infty\right) \text { 'at least' reading }
\end{aligned}
$$

For a comparative sentence, we analyze the comparative morpheme more/-er as the default differential: $(0,+\infty)$, which represents a positive interval allowing for the most possibilities (see (35)). ${ }^{8}$ Little changes the polarity of an interval (see (36)) so that in a less-than comparative, the default differential less means $(-\infty, 0)$, i.e., a negative interval allowing for the most possibilities (see (37)). Obviously, the direction of inequality is shifted when the polarity of the differential is altered.

$$
\begin{aligned}
& {[[\text { more } / \text {-er }]]_{\langle d t\rangle} \stackrel{\text { def }}{=}(0,+\infty)} \\
& {[[\text { little }]]_{\langle d t, d t\rangle} \stackrel{\stackrel{\text { def }}{=}}{=} \lambda I_{\langle d t\rangle} \cdot[0,0]-I} \\
& \left.[[\text { less }]]_{\langle d t\rangle} \stackrel{\text { def }}{=}[[\text { little }]][\text { more/-er }]\right]=(-\infty, 0)
\end{aligned}
$$

As shown in (38), [(th)-an] takes two intervals as arguments, one serving as the comparative standard and the other the differential, and returns the interval that serves as the comparative standard.

$$
[[(\mathrm{th})-\mathrm{an}]]_{\langle d t,\langle d t, d t\rangle\rangle} \stackrel{\text { def }}{=} \lambda I_{\text {stdd }} \cdot \lambda I_{\text {diff }} \cdot \imath I\left[I-I_{\text {stdd }}=I_{\text {diff }}\right]
$$

Based on the definitions in (34)-(38) and the computation mechanism shown in (33), the semantic derivation for more-than comparative (39a) and less-than comparative (39b) is shown in (40). In (40), [[the] applies to the set of intervals $\lambda I^{\prime} .\left[\forall x\left[\operatorname{boy}(x) \rightarrow \operatorname{Speed}(x) \subseteq I^{\prime}\right]\right.$ and returns the most informative interval that includes every boy's height (see (41)). The notion of informativeness often depends on the precision level of measurement in a context. We can write the definite description $\left[[\right.$ the $]\left[\lambda I^{\prime} \cdot\left[\forall x\left[\operatorname{boy}(x) \rightarrow \operatorname{Speed}(x) \subseteq I^{\prime}\right]\right]\right]$ as $\left[I_{\text {every-boy's-height-MIN }}, I_{\text {every-boy's-height-MAx }}\right]$.

8 Analyzing the comparative morpheme more/-er as an interval that serves as the default differential is independently motivated (see Zhang \& Ling 2015 as well as Greenberg 2010; Thomas 2010, 2011). For comparatives with further restriction on differentials, e.g., more than 2 inches taller, or at most 2 inches less tall, see Zhang \& Ling 2015, 2017a for a more detailed analysis. 
a. Lucinda is taller than every boy is.

b. Lucinda is less fast than every boy is.

a. $\quad[[(39 \mathrm{a})]] \Leftrightarrow \operatorname{Hgt}($ Lucinda $) \subseteq \imath I[I-[$ than every boy is (tall) $]]=(0,+\infty)]$ $\Leftrightarrow \operatorname{Hgt}(\mathrm{Lu}) \subseteq \imath I[I-[$ the $\left.]]\left[\lambda I^{\prime} .\left[\forall x\left[\operatorname{boy}(x) \rightarrow \operatorname{Hgt}(x) \subseteq I^{\prime}\right]\right]\right]=(0,+\infty)\right]$ $\Leftrightarrow \operatorname{Hgt}($ Lucinda $) \subseteq\left(I_{\text {every-boy's-height-MAX }},+\infty\right)$

b. $\quad[[(39 b)] \Leftrightarrow \operatorname{Hgt}($ Lucinda $) \subseteq i I[I-[[$ than every boy is (tall) $]]=(-\infty, 0)]$ $\Leftrightarrow \operatorname{Hgt}(\mathrm{Lu}) \subseteq \imath I\left[I-[[\right.$ the $\left.]]\left[\lambda I^{\prime} \cdot\left[\forall x\left[\operatorname{boy}(x) \rightarrow \operatorname{Hgt}(x) \subseteq I^{\prime}\right]\right]\right]=(-\infty, 0)\right]$ $\Leftrightarrow \operatorname{Hgt}($ Lucinda $) \subseteq\left(-\infty, I_{\text {every-boy's-height-MIN }}\right)$

$$
[\text { the }]]_{\langle\langle d t, t\rangle, d t\rangle} \stackrel{\text { def }}{=} \lambda P_{\langle d t, t\rangle} \cdot l I\left[P(I) \wedge \neg \exists I^{\prime} \neq I\left(P\left(I^{\prime}\right) \wedge P\left(I^{\prime}\right)>_{\text {more informative }} P(I)\right)\right]
$$

As shown in (40a), without further restriction for differentials, the upper bound of the differential in a more-than comparative is infinity. Consequently, the upper bound of the resultant comparative subject is also infinity, and apparently, it seems that only the lower bound of the comparative subject matters, which is computed from the upper bound of the comparative standard (plus 0 - the lower bound of the differential). Therefore, when a than-clause denotes a range of values in a more-than comparative, we always care about its upper bound, and the ' $>$ MAX' reading is always available (see the generalization in (20) and Table 1).

Similarly, from the derivation in (40b), we can conclude that when a than-clause denotes a range of values in a less-than comparative, we always care about its lower bound (which contributes to the upper bound of the comparative subject), and the ' $<$ MIN' reading is always available.

The upshot here is that in both more-than and less-than comparatives, the upper and the lower bound of the comparative standard always contribute to the semantics of the comparative subject in a uniform way (see (33)). A comparative sentence is similar to a sentence with cumulative reading (e.g., exactly 3 boys saw exactly 5 movies) in that there is no scope taking among its three degree-related expressions.

\subsection{Than-clauses analyzed as short answers to $w h$-questions}

Here we adopt the categorial approach to the semantics of questions and answers (see Hausser \& Zaefferer 1978; Hausser 1983; Von Stechow \& Zimmermann 1984; Ginzburg \& Sag 2000; Guerzoni \& Sharvit 2007; Krifka 2011; Barker 2016; Xiang 2016; etc). Within this categorial framework, a question denotes a function, and its short answer denotes the argument such that applying the function to this argument results in a true proposition, i.e., the long answer, as illustrated in (42).

$\left[\left[\right.\right.$ Who came to the party?] $=\lambda x_{e} . x$ came to the party
a. John.
Short answer (or fragment answer)
b. John came to the party.
Long answer (or propositional answer) 
Ambiguous than-clauses and the mention-some reading

As we have shown in (40) (the than-clause is repeated here in (43a)), within the interval-arithmetic-based analysis for comparatives, the semantics of the than-clause is derived by applying [[the]] to a set of intervals (here $\lambda I \cdot \forall x[\operatorname{boy}(x) \rightarrow \operatorname{Height}(x) \subseteq$ $\left.\left.I^{\prime}\right]\right)$ so that $[$ the] picks out the context-dependent, most informative interval that includes every boy's height. It is evident that this set of intervals can be considered a function standing for a wh-question, i.e., how tall is every boy (see (43b)). Thus the context-dependent, most informative interval (43a) is exactly the short answer to this $w h$-question (43b): applying the function to this most informative interval returns a true proposition. In other words, the semantics of a than-clause and the short answer to the wh-question corresponding to this than-clause are equivalent. ${ }^{9}$

$$
\begin{array}{ll}
\text { a. } & [\text { than every boy is (tall) })]=[[\text { the }]]\left[\lambda I . \forall x\left[\operatorname{boy}(x) \rightarrow \operatorname{Height}(x) \subseteq I^{\prime}\right]\right] \\
\text { b. } & {[\text { how tall is every boy }]=\lambda I . \forall x\left[\operatorname{boy}(x) \rightarrow \operatorname{Height}(x) \subseteq I^{\prime}\right]}
\end{array}
$$

The example (44) also provides support for an answerhood-based view for thanclauses. In some English dialects, than-clauses can explicitly contain wh-questions.

$\%$ This table is longer than how wide the door is.

Then a worth-noting issue is how to give a short answer to a pair-list $w h$-question like how tall is every boy. As illustrated in (45), given this context in which each of the three girls ate a different kind of fruit, here the $w h$-question typically needs a pair-list answer. As shown in (45a), using a conjunctive form yields a sum of entities, and native speakers of English all judge (45a) as a bad answer under the given context. In contrast, for many native speakers, using a disjunctive form yields a much better answer (see (45b)). According to some of our consultants who do not like (45b), the short answer (45b) eventually leads to a corresponding long answer with two possible readings, i.e., the ' $O R>\forall$ ' and the ' $\forall>$ OR' reading for the sentence every girl ate an apple, a banana, or a peach, and their uneasiness with (45b) seems due to the availability of the 'OR $>\forall$ ' reading, which is false under the given context. The consensus is that $(45 \mathrm{c})$ is the best short answer here, suggesting that for a pair-list $w h$-question, its short answer should denote a range of possible values in a rather general way and somehow overlook details. ${ }^{10}$

9 The sentences Lucinda is taller than every boy is and Lucinda's height exceeds every boy's (height) have the same meaning, so one might be wondering whether the semantics of the than-clause in (43a) and the relational DP every boy's height are also equivalent. However, in the sentence Lucinda knows every boy's height, it is evident that the DP every boy's height serves as the propositional argument of know and cannot be replaced by an interval, suggesting that the semantics of a relational DP and the short answer to a $w h$-question are not exactly the same. It seems that the semantics of a relational DP might be flexible between a propositional answer and a short answer. (See also Barker 2016 for a more detailed discussion on the semantics of relational DPs.)

10 See Zhang In prep. for more discussion on the notion of convex sets in answerhood. 
(45) Context: Mary ate an apple; Sue ate a banana; Kate ate a peach. QUESTION: What did every girl eat?
a. \# An apple, a banana, and a peach.
\# A sum of entities
b. \% An apple, a banana, or a peach.
c. $\quad \checkmark$ A piece of fruit.
$\checkmark$ A range of possible values

Therefore, similarly, for comparatives like Lucinda is taller than every boy is, the than-clause should also denote a range of degrees, not a sum of degrees (see (46), cf. Beck 2014; Dotlačil \& Nouwen 2016). Moreover, as we have proposed, a than-clause should denote an interval, i.e., a convex set, which means that details between its endpoints should be overlooked and not affect further derivation.

Context: John is $6^{\prime}$ tall. Bill is $6^{\prime} 2^{\prime \prime}$ tall. Fred is $6^{\prime} 5^{\prime \prime}$ tall. QUESTION: How tall is every boy? (Lucinda is taller than every boy is.)
a. At least $6^{\prime}:\left[6^{\prime},+\infty\right)$
b. Between $6^{\prime}$ and $6^{\prime} 5^{\prime \prime}:\left[6^{\prime}, 6^{\prime} 5^{\prime \prime}\right]$
c. $\# 6^{\prime}, 6^{\prime} 2^{\prime \prime}$, and $6^{\prime} 5^{\prime \prime}$.

A less informative interval The most informative interval \# A sum of degrees

In sum, we have shown that a than-clause can be considered a short answer to its corresponding $w h$-question, and it denotes a convex set. This has two consequences. First, analyzing the semantics of a than-clause as a convex set provides further support for our interval-arithmetic-based recipe in which only the endpoints of the comparative standard matter for computing the meaning of a comparative sentence. Second, a than-clause, as a short answer to a wh-question, should inherit relevant properties of the answerhood for this wh-question.

\subsection{Mention-some vs. mention-all answerhood}

Here we show why and how the use of existential priority modals in wh-questions gives rise to 'mention-some/mention-all' ambiguity for answerhood.

Usually, we ask questions to seek information, and a good answer should be complete and truthful. For example, in (47), under the given context, (47a) is infelicitous, and the short answers (47b-i) and (47b-iii) are either misleading or not informative enough, suggesting that a complete answer should be a mention-all answer, i.e., a good short answer is unique and includes all entities such that applying the function ' $\lambda x . x$ came to the party' to each of them results in a true proposition.

(47) Context: There are three people under discussion: John, Mary, and Bill. John and Mary came to the party; Bill didn't. Sue only knows that John came to the party but has no information about Mary or Bill.

a. \# Sue knows who came to the party. 
Ambiguous than-clauses and the mention-some reading

b. $\quad\left[\right.$ Who came to the party?]] $=\lambda x \cdot x$ came to the party ${ }^{11}$
(i) \# John.
Incomplete $\sim$ misleading
(ii) $\checkmark$ John and Mary.
Complete: a mention-all answer
(iii) \# John or Mary.
Not informative enough

In contrast, the use of an existential priority modal licenses mention-some answers. Under the given context, (48a) is felicitous, and all the short answers in (48b) are good, suggesting that here mention-some and mention-all answers are all qualified as complete. Moreover, as shown in (48b-ii) and (48b-iii), in this case, there are two forms for mention-all answers: conjunctive and disjunctive.

ConteXT: There are three places to get gas in Cambridge: $\mathrm{X}, \mathrm{Y}$, and Z. Kim only knows about X but has no idea about Y or Z.

a. $\checkmark$ Kim knows where we can get gas in Cambridge.

b. $\quad[$ Where can we get gas? ]] $=\lambda x$. $\diamond$ we get gas at $x$
(i) $\checkmark \mathrm{X}$
$\checkmark$ Mention-some answer
(ii) $\checkmark \mathrm{X}, \mathrm{Y}$, and Z
$\checkmark$ Conjunctive mention-all answer
(iii) $\checkmark \mathrm{X}, \mathrm{Y}$, or Z
$\checkmark$ Disjunctive mention-all answer

To account for the availability of mention-some answers for questions containing an existential modal ( $\diamond$-question), Fox $(2013,2016)$ and Xiang (2016) have proposed a structural account based on the notion of max-informativeness (see (49)): a complete answer is defined as a max-informative answer, and max-informative answer(s) cannot be asymmetrically entailed by any member in the answer space.

(49) Given a set of propositions $\alpha$, the set of its max-informative members is: $\{p \mid p \in \alpha \wedge \forall q[q \in \alpha \rightarrow q \not \subset p]\}$.

The basic idea is that there is a covert distributivity operator, and the scopal interaction between this distributivity operator and the modal $\diamond$ generates different answer spaces. (i) When DIST takes wider scope (see (50a)), the answer space is closed under conjunction, and there is a unique true and max-informative proposition, which is the mention-all answer. (ii) When $\diamond$ takes wider scope (see (50b)), the answer space is not closed under conjunction, and therefore, both $\diamond p$ and $\diamond q$ are max-informative (i.e., complete) and thus they are good mention-some answers.

Assume that $p$ and $q$ are semantically independent and non-contradictory ( $\alpha$ and $\beta$ are Hamblin sets; untruthful propositions are crossed out),

11 Sometimes, it seems that we can provide a for-example answer for questions like (47b), so some approaches to the mention-some answer are based on pragmatic factors (e.g., van Rooij 2008). However, given the distribution of the mention-some reading (especially in embedded questions), it is evident that there should be some grammatical or structural constraints (see Xiang 2016). 
a. $\quad$ DIST $>\diamond: \alpha=\{\diamond p, \diamond q, \diamond p \wedge \diamond q\}$

b. $\diamond>$ DIST: $\beta=\{\underline{\diamond p}, \diamond q, \overline{\nabla(p \wedge q)}\}$ closed under $\wedge$

not closed under $\wedge$

Without going into technical details, there is a crucial problem for this approach. The reasoning underlying this max-informative approach should work in the same way for all existential modals, predicting that all $\diamond$-questions license mentionsome answers (even when they are embedded questions), but as (51) shows, an existential epistemic modal (here might) does not license mention-some answers at all (see Groenendijk \& Stokhof 1984; Dayal 2016). Therefore, the upshot here is that existential priority modals, or permission-related modals, are special. A good account for the 'mention-some/mention-all' ambiguity should be based on this.

CONTEXT: There are three people under discussion: John, Mary, and Bill. John and Mary might come to the party; Bill won't. Sue only knows about John's potential availability but has no idea about Mary or Bill.

a. \#Sue knows who might come to the party.

b. - Who might come to the party? - \# John.

Here we propose to follow Ross (1944) and Barker (2016) and adopt the idea that the logic of obligation and permission behaves dramatically different from other sorts of ordinary reasoning in being resource-sensitive. Roughly speaking, when we use $w h$-questions with existential priority modals, the main purpose is not to seek information, but to seek permission (or more generally, resource). Information seeking and resource seeking follow different principles.

For information seeking, we naturally consider information immaterial and eternal, and thus, we intuitively feel that the more information, the better, and it is reasonable to assume that the answerhood for information-seeking questions is based on the principle of max-informativeness.

However, resource should be considered consumable, and thus not only what kind of resource matters (e.g., whether $A$ is permitted or $B$ is permitted), but also how much resource matters (e.g., whether there are two permissions $A$ and $B$ that can be used in a cumulative way or just one permission, say one of $A$ and $B$ ). Therefore, a complete answer for resource-seeking questions should grant enough permission, and max-informativeness does not matter so much here.

Following Lokhorst (1997) and Barker (2010), we adopt Girard's (1987) Linear Logic, which is a resource-sensitive logic, to explain how in the case of (48), for the question where can we get gas, both the disjunctive answer $X, Y$, or $Z$ and the mention-some answer $X$ grant enough permission and are complete answers.

Within Girard's Linear Logic, there are two connectives for conjunction - \& and $\otimes-$ and two for disjunction $-\oplus$ and $\mathcal{X}$. \& and $\oplus$ are additive operators, while $\otimes$ and $\not \partial$ are multiplicative operators. $\multimap$ means linear implication. 
Ambiguous than-clauses and the mention-some reading

Here is an example illustrating the difference between additive and multiplicative conjunction. The additive conjunction of Linear Logic works in the same way as the conjunction of classical logic, and thus, from $A \multimap B$ and $A \multimap C$, it follows that $A \multimap B \& C$. However, $A \multimap B \otimes C$ does not follow here, but $A \otimes A \multimap B \otimes C$ follows. The intuition is that if you have $\$ 1$, you can get a beer, and you can get a coke, so you have two options, but you cannot get both. To get both, you need to have $\$ 2$. So $A \multimap B \& C$ actually means 'if $A$ then $B$ else $C$ '.

Apparently, it seems that additive conjunction $\&$ has some kind of disjunctive flavor, but additive conjunction $\&$ is different from additive disjunction $\oplus$. In the case of $A \multimap B \& C$, you can decide whether to get a beer or a coke, but in the case of $A \multimap B \oplus C$, it is not up to you to decide. In other words, $\oplus$ is a free choice $o r$.

One more element needed is how to express permissions within Linear Logic. We analyze allowed as a strong permission: if $A$ is allowed, not only $A$ is not forbidden, but also the permission of $A$ is explicitly granted. We follow Lokhorst (1997) and Barker (2010) and write $A$ is allowed as $A \multimap \delta$, meaning 'it is OK if we do $A$ '.

Now we assume that in permission-related sentences, natural language or means additive disjunction. Therefore, as shown in (52), ${ }^{12}$ using either the disjunctive form $A \oplus B$ (see (52b)) or a mention-some answer like $A$ (see (52c)) grants enough permission for taking actions (e.g., choosing a place to get gas).

$$
\text { a. }(A \oplus B) \multimap \delta \equiv(A \multimap \delta) \&(B \multimap \delta)
$$

i.e., if blindly doing anything indeterministic between $A$ and $B$ is $\mathrm{OK}$, then mindfully choosing $A$ is $\mathrm{OK}$, and mindfully choosing $B$ is $\mathrm{OK}$; if mindfully choosing $A$ is $\mathrm{OK}$, and mindfully choosing $B$ is $\mathrm{OK}$, then blindly doing anything indeterministic between $A$ and $B$ is $\mathrm{OK}$.

b. $(A \oplus B) \multimap \delta \vdash(A \& B) \multimap \delta$

i.e., if blindly doing anything indeterministic between $A$ and $B$ is $\mathrm{OK}$, then mindfully choosing between $A$ and $B$ is $\mathrm{OK}$.

c. $\quad A \multimap \delta \vdash(A \& B) \multimap \delta$

i.e., if doing $A$ is $\mathrm{OK}$, then mindfully choosing between $A$ and $B$ is $\mathrm{OK}$.

Finally, in the example (48), we certainly do not need to go to all three places to get gas, and thus for the conjunctive mention-all answer, we propose that this conjunction takes wider scope. Therefore, the meanings of the three answers are shown in (53), and they are all complete answers for a resource-seeking question.
a. $\mathrm{X}$ $\mathrm{X} \multimap \delta$
b. $\mathrm{X}, \mathrm{Y}$, and $\mathrm{Z}$
$(\mathrm{X} \multimap \delta) \&(\mathrm{Y} \multimap \delta) \&(\mathrm{Z} \multimap \delta)$
c. $\mathrm{X}, \mathrm{Y}$, or $\mathrm{Z}$
$(\mathrm{X} \oplus \mathrm{Y} \oplus \mathrm{Z}) \multimap \delta$

12 An online Linear Logic Prover is available here: http://bach.istc.kobe-u.ac.jp/llprover/. 


\section{Deriving the ambiguity of the Lucinda sentence in (1)}

The ambiguity of the Lucinda example follows naturally from our proposal.

First, the use of a permission-related existential modal in its than-clause leads to short answers with mention-some (see (54a)) and mention-all (see (54b)) readings. Then, these answers enter into the semantic mechanism of comparatives in a uniform way, leading to a ' $\angle$ MAX' and a ' $<$ MIN' reading respectively.

$[[$ than allowed] $]=$ the short answer to how fast is Lucinda allowed to drive

a. A mention-some answer: [50mph, 50mph] $\sim$ ' $<$ MAX' reading

(i) $\quad[$ th(an) $\lambda I$. (Lu is) allowed (to drive $I$ fast) $]]=[50 \mathrm{mph}, 50 \mathrm{mph}]$

(ii) $\quad$ Speed (Lucinda $) \subseteq \imath I[I-[50 \mathrm{mph}, 50 \mathrm{mph}]=(-\infty, 0)]$ $\Leftrightarrow \operatorname{Speed}($ Lucinda $) \subseteq(-\infty, 50 \mathrm{mph})$

b. Disjunctive mention-all answer: $[35 \mathrm{mph}, 50 \mathrm{mph}] \sim$ ' $<$ MIN'reading

(i) $[[\operatorname{th}($ an) $\lambda I$. (Lu is) allowed (to drive $I$ fast) $]]=[35 \mathrm{mph}, 50 \mathrm{mph}]$

(ii) $\quad$ Speed (Lucinda $) \subseteq \imath I[I-[35 \mathrm{mph}, 50 \mathrm{mph}]=(-\infty, 0)]$ $\Leftrightarrow \operatorname{Speed}($ Lucinda $) \subseteq(-\infty, 35 \mathrm{mph})$

In fact, under the context in (1), the permission is also the obligation, i.e., Lucinda is required to drive between 35 and $50 \mathrm{mph}$. However, for $w h$-questions with obligation-related modals, mention-some answers are unavailable: if a notso-precise range of values is required, no particular interval within it (i.e., a more precise range) is required. The only exception comes with the lower bound of this range (say $35 \mathrm{mph}$ ), which is the short answer when the question is interpreted in an 'at least' way (see (34b-ii)). This explains why comparatives with obligation-related modals have a bias towards MIN-related readings and are less subject to ambiguity.

\section{Conclusion}

In this paper, we have attributed the ambiguity of comparatives like the Lucinda example to the 'mention-some/mention-all' ambiguity in interpreting their thanclause: the ultimate source of this ambiguity is the use of existential priority modals in permission-seeking $w h$-questions. Overall, our account consists of: (i) an intervalarithmetic-based semantics for unifying the contribution of maximum and minimum values expressed by than-clauses, (ii) a short-answer-based view for connecting the interpretation of than-clauses and the answerhood for corresponding $w h$-questions, and (iii) a resource-sensitive account for the ambiguous answerhood rooted in the use of permission-related existential modals. Each of these parts is independently motivated, and our proposal suggests that richer logical systems and mathematical tools enable us to have new insights into human language capacity. Technical details and comparison with related work will be included in our future work. 
Ambiguous than-clauses and the mention-some reading

\section{References}

Alrenga, Peter \& Christopher Kennedy. 2014. No more shall we part: Quantifiers in English comparatives. Natural Language Semantics 22(1), 1-53.

Barker, Chris. 2010. Free choice permission as resource-sensitive reasoning. Semantics and Pragmatics 3, 10-1.

Barker, Chris. 2016. Why relational nominals make good concealed questions. Lingua 182, 12-29.

Beck, Sigrid. 2010. Quantifiers in than-clauses. Semantics and Pragmatics 3(1), $1-72$.

Beck, Sigrid. 2013. Lucinda driving too fast again - the scalar properties of ambiguous than-clauses. Journal of Semantics 30(1), 1 - 63 (ffr011).

Beck, Sigrid. 2014. Plural predication and quantified 'than'-clauses. In Luka Crnič \& Uli Sauerland (eds.), The Art and Craft of Semantics: A Festschrift for Irene Heim 1, 91-115. MIT Working Papers in Linguistics 70.

Beck, Sigrid \& Hotze Rullmann. 1999. A flexible approach to exhaustivity in questions. Natural Language Semantics 7(3), 249-298.

Büring, Daniel. 2007a. Cross-polar nomalies. In T. Friedman \& M. Gibson (eds.), Semantics and Linguistic Theory (SALT) 17, 37-52. Ithaca, NY: Cornell University.

Büring, Daniel. 2007b. More or less. In Proceedings of the 43th Annual Regional Meeting of Chicago Linguistic Society, 3-17. Chicago Linguistic Society.

Crnič, Luka. 2017. More on less. In Andrew Lamont and Katerina A. Tetzloff (eds.), NELS 47: Proceedings of the 47th Meeting of the North East Linguistic Society.

Dayal, Veneeta. 2004. The universal force of free choice any. Linguistic Variation Yearbook 4(1), 5-40.

Dayal, Veneeta. 2016. Questions. Oxford University Press.

Dotlačil, Jakub \& Rick Nouwen. 2016. The comparative and degree pluralities. Natural Language Semantics 24(1), 45-78.

Fox, Danny. 2013. Mention-some readings of questions. MIT seminar notes.

Fox, Danny. 2016. Mention some, reconstruction, and free choice. "Attitudes and Questions" Workshop notes.

Ginzburg, Jonathan \& Ivan Sag. 2000. Interrogative investigations. Stanford: CSLI publications.

Greenberg, Yael. 2010. Additivity in the domain of eventualities (or: Oliver Twist's more). In Martin Prinzhorn, Viola Schmitt \& Sarah Zobel (eds.), Proceedings of Sinn und Bedeutung 14, 151-167.

Groenendijk, Jeroen \& Martin Stokhof. 1984. Studies on the semantics of questions and the pragmatics of answers. Amsterdam, the Netherlands: Universiteit van Amsterdam $\mathrm{PhD}$ dissertation. 
Guerzoni, Elena \& Yael Sharvit. 2007. A question of strength: on NPIs in interrogative clauses. Linguistics and Philosophy 30(3), 361-391.

Hacquard, Valentine. 2005. Aspect and actuality entailment: Too and enough constructions. In Emar Maier, Corien Bary \& Janneke Huitink (eds.), Proceedings of Sinn und Bedeutung 9, 116-130.

Hacquard, Valentine. 2006. Aspects of too and enough constructions. In Semantics and Linguistic Theory (SALT) 15, 80-96. Citeseer.

Hausser, Roland \& Dietmar Zaefferer. 1978. Questions and answers in a contextdependent Montague grammar. In Formal Semantics and Pragmatics for Natural Languages, 339-358. Springer.

Hausser, Roland R. 1983. The syntax and semantics of english mood. In Questions and answers, 97-158. Springer.

Heim, Irene. 2006a. Little. In M. Gibson \& J. Howell (eds.), Semantics and Linguistic Theory (SALT) 16, 35-58. Ithaca, NY: Cornell University.

Heim, Irene. 2006b. Remarks on comparative clauses as generalized quantifiers. Manuscript, MIT.

Krasikova, Sveta. 2008. Quantifiers in comparatives. In Atle Grønn (ed.), Proceedings of Sinn und Bedeutung 12, 337-352. Oslo: ILOS 2008 (ISBN 978-8292800-00-3).

Krasikova, Svetlana. 2011. Modals in comparatives. Tübingen, Baden-Württemberg, Germany: Universität Tübingen $\mathrm{PhD}$ dissertation.

Krifka, Manfred. 2011. Questions. In Klaus Heusinger, Claudia Maienborn \& Paul Portner (eds.), Semantics: An international handbook of Natural Language Meaning 2, 1742-1785. Berlin: Mouton de Gruyter.

Lokhorst, Gert-Jan C. 1997. Deontic Linear Logic with Petri Net Semantics. Erasmus University, Department of Philosophy.

Meier, Cécile. 2002. Maximality and minimality in comparatives. In Graham Katz, Sabine Reinhard \& Philip Reuter (eds.), Proceedings of Sinn und Bedeutung 6, $275-287$.

Meier, Cécile. 2003. The meaning of too, enough, and so... that. Natural Language Semantics 11(1), 69-107.

Moore, Ramon E. 1979. Methods and Applications of Interval Analysis. SIAM.

van Rooij, Robert. 2008. Comparatives and quantifiers. In O. Bonami \& P. Cabredo Hofherr (eds.), Empirical Issues in Syntax and Semantics 7, 423-444. http://www.cssp.cnrs.fr/eiss7.

Ross, Alf. 1944. Imperatives and logic. Philosophy of Science 11(1), 30-46.

Rullmann, Hotze. 1995. Maximality in the semantics of wh-constructions. Amherst, MA: University of Massachusetts Amherst PhD dissertation.

Schwarzchild, Roger \& Karina Wilkinson. 2002. Quantifiers in comparatives: A semantics of degree based on intervals. Natural Language Semantics 10(1), 
Ambiguous than-clauses and the mention-some reading

$1-41$.

Schwarzschild, Roger. 2008. The semantics of comparatives and other degree constructions. Language and Linguistics Compass 2(2), 308-331.

Seuren, Pieter A. M. 1979. Meer over minder dan hoeft. De Nieuwe Taalgids 72(3), 236-239.

Thomas, Guillaume. 2010. Incremental more. In Semantics and Linguistic Theory (SALT) 20, 233-250.

Thomas, Guillaume. 2011. Another additive particle. In Semantics and Linguistic Theory (SALT) 21, 634-651.

Von Stechow, Arnim. 1984. Comparing semantic theories of comparison. Journal of Semantics 3(1), 1-77.

Von Stechow, Arnim \& Thomas Ede Zimmermann. 1984. Term answers and contextual change. Linguistics 22(1), 3-40.

Xiang, Yimei. 2016. Interpreting questions with non-exhaustive answers. Cambridge, MA: Harvard University PhD dissertation.

Zhang, Linmin. 2017. Sufficiency and excess: The semantics of enough and too. Sinn und Bedeutung 22.

Zhang, Linmin. In prep. Convex set and answerhood. Manuscript.

Zhang, Linmin \& Jia Ling. 2015. Comparatives revisited: Downward-entailing differentials do not threaten encapsulation theories. In Thomas Brochhagen, Floris Roelofsen \& Nadine Theiler (eds.), Proceedings of the 20th Amsterdam Colloquium, 478 - 487.

Zhang, Linmin \& Jia Ling. 2017a. LiTTLE: Not a dichotomy-based negation operator, but a trivalence-based polar opposition operator. In Aaron Kaplan, Abby Kaplan, Miranda K. McCarvel \& Edward J. Rubin (eds.), Proceedings of the 34th West Coast Conference on Formal Linguistics, Cascadilla Press.

Zhang, Linmin \& Jia Ling. 2017b. The semantics of English clausal comparatives: An interval-arithmetic-based approach. Manuscript.

Linmin Zhang

Psycholinguistics \& Cognition Lab

Department of Psychology \& Program in Linguistics

Concordia University

SP-244 (Loyola Campus), 7141 Sherbrooke Street West

Montréal, Québec, Canada H4B 1R6

linmin.zhang@nyu.edu, zhanglinmin@gmail.com
Jia Ling

Department of Biology

New York University

1009 Silver Center

100 Washington Square East

New York, NY 10003-6688

j14327@nyu.edu 